\title{
Passive Cooling Load Ratio Method
}

\author{
Ana I. F. Nunes ${ }^{\mathrm{a}, \mathrm{b}}$, Marta J. N. Oliveira Panãoa,* \\ ${ }^{a}$ National Laboratory of Energy and Geology (LNEG), Estrada do Paço Lumiar, 22, \\ 1630-038 Lisbon, Portugal \\ ${ }^{b}$ University of Lisbon, DEGGE, Campo Grande, 1149-016 Lisboa, Portugal
}

\begin{abstract}
The method Passive Cooling Load Ratio (PCLR) is an innovative simplified method which calculates the monthly cooling energy needs of a thermal zone where passive cooling systems are installed using the variables: cooling energy load and passive cooling potential. This new method is based on the Solar Load Ratio (SLR) that was previously developed for solar heating systems. Although, PCLR was theoretically developed for any passive cooling system, here it is applied to passive cooling based on ventilation strategies. In addition, this paper presents its application to an office room ventilation using: i) forced cooled air from an earth-to-air heat exchanger (EAHE) and ii) natural induced air by a solar chimney from the EAHE. Correlations were obtained for those systems, using the parameters that describe the local climate, the system type and its dimensions. The numerical model used to obtain the correlation functions when one of the systems is installed, associates previously developed numerical models with 5R1C model of ISO 13790. However, the PCLR method can be used to accurately estimate the cooling energy needs without using complex models for simulation. The error for all systems does not overcomes $5.2 \%$, which is an acceptable variation for a
\end{abstract}

\footnotetext{
${ }^{*}$ Corresponding author at: National Laboratory of Energy and Geology (LNEG). Tel.: +351 210924600 (4338); fax: +351 217166966.

Email address: marta.oliveira@lneg.pt (Marta J. N. Oliveira Panão)
} 
simplified method.

Keywords: passive cooling, PCLR, 5R1C model, earth-to-air heat exchanger, solar chimney, cooling energy needs, simplified method

\section{Introduction}

Currently, developed countries stress to reduce energy consumption in buildings that accounts for $20 \%$ to $40 \%$ of the total final energy [1]. The expected decrease caused by the improvement of the equipments energy efficiency is, by far, exceeded by the increase in number and use of domestic appliances, in residential sector, and electrical appliances such as information and communication technologies, in service sector [2]. To change this trend, a new kind of buildings should be further developed, the so called "nearly Zero Energy Buildings" (nZEB) [3], which should lay on two complementary action lines: reduce the energy demand and use renewable energy sources. For the near future, starting from 2020, all new buildings in the European Union must be nZEB, according to European Union Directive on Energy Performance of Buildings [4]. To pave the way for decreasing buildings energy demand, it is imperious to apply passive cooling and solar heating systems according to climate requirements, while keeping the comfort conditions for its occupants.

The calculation methods for cooling energy needs of International Standard ISO 13790 [5], both hourly and monthly, account for the beneficial effect of the solar shading, thermal inertia and radiative cooling. Other cooling strategies, such as ventilation, can be accounted, even if ISO 13790 does not explicitly define how, by the use of the adjustment factor correcting the external air temperature [6]. This approach is, however, difficult to implement because such adjustment factor is not defined for passive cooling systems. 
An explicit calculation methodology for passive cooling systems, such as for passive solar heating, is still missing; therefore, it can be argued that simplified methods for passive cooling systems should be developed and included in ISO 13790.

The term "passive cooling system" is here extended to any strategy, design feature or technology to the control or reduction of the cooling energy needs. Typically, passive cooling systems require no use of other sources of energy, besides those naturally available, or their use is very low compared to the benefit effect provided.

\section{Passive Cooling Load Ratio method (PCLR)}

\subsection{The concept}

The method Passive Cooling Load Ratio (PCLR) aims at bridging the ISO 13790 need for improvement by providing a simplified method for estimating cooling energy needs of a thermal zone, depending on the characteristics of the passive cooling system and the cooling energy load, i.e. the total cooling to be extracted. The PCLR method conceptually follows the Solar Load Ratio (SLR) [7], which applies to the characterization of passive solar heating systems.

The main idea of PCLR is to provide an estimative for cooling energy needs avoiding running simulations or complex models, whenever passive cooling systems are used. Therefore PCLR, as all simplified methods, quantifies the energy needs within an acceptable uncertainty or bandwidth, which for the monthly method of ISO 13790 was found to be 10\% [8], using the parameter of standard deviation.

This innovative method proposed in this paper uses the PCLR parameter, defined as the ratio between the system cooling potential, here applied for 
ventilation $Q_{v e}$, and the cooling energy load $Q_{g n}$, by

$$
\mathrm{PCLR}=\frac{Q_{v e}}{Q_{g n}}
$$

Cooling energy needs can be directly calculated by

$$
Q_{n d}=(1-\mathrm{PCF}) Q_{g n}
$$

with PCF as the Passive Cooling Fraction, representing the contribution of the passive cooling system to extract the cooling energy load (see Fig.1). The PCLR method, as SLR's, is based on empirical correlations of PCF as a function of PCLR depending on the system technology.

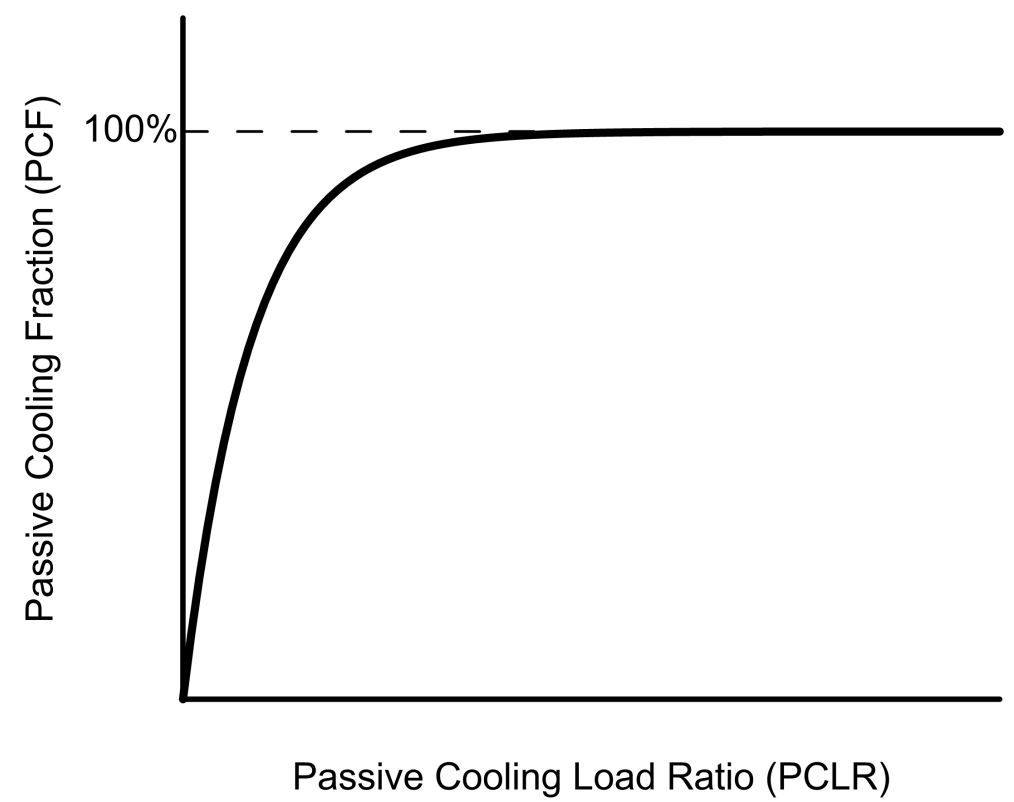

Figure 1: Passive Cooling Fraction as a function of Passive Cooling Load Ratio.

The cooling energy load, $Q_{g n}$, represents the monthly cooling energy that needs to be extracted from the thermal zone and can be estimated by

$$
Q_{g n}=Q_{\text {sol }}+Q_{\text {int }}
$$


For the sake of method simplicity, the energy load due to internal gains, $Q_{\text {int }}$, includes only the sensible heat depending on the number of occupants, electric equipments and lighting. The solar gains, $Q_{\text {sol }}$, are monthly computed.

It is noteworthy that PCF could be extended to other passive cooling systems as long as it is possible to quantify the system cooling potential, similarly to what is defined for the ventilation potential $Q_{v e}$.

\subsection{Methodology to set the empirical correlations}

Making the PCLR method applicable to a specific passive cooling system, means to set the empirical parameters that correlate PCF with PCLR.

This procedure implies the previous knowledge of the cooling energy needs for a large set of cases characterized by different PCLR. For each PCLR computed by Eq. 1, a PCF value needs to be found by rearranging Eq. 2 as

$$
\mathrm{PCF}=1-\frac{Q_{n d}}{Q_{g n}}
$$

The passive cooling systems selected to test the methodology were twofold: A) the forced ventilation with air from an earth-to-air heat exchanger (EAHE) and $\mathrm{B}$ ) the solar chimney (SC) induced ventilation with air from the EAHE (see Fig. 2). The ventilation system applies to a single thermal zone.

In order to calculate cooling energy needs of the thermal zone with systems A or B, three models published in the literature were used: i) the outlet air temperature of an EAHE [9], ii) the air flow induced by a solar chimney [10] and iii) the 5R1C hourly energy balance of ISO 13790 [5].

System A is modeled by an EAHE associated with the 5R1C energy balance model. System B is modeled by the solar chimney associated with the previous two. 


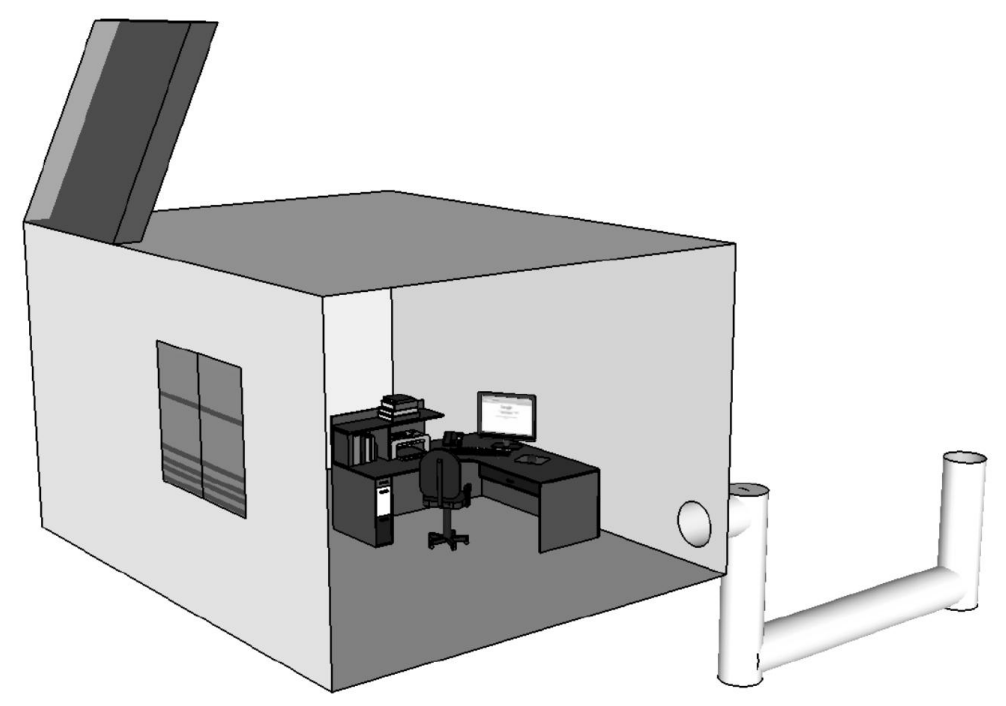

Figure 2: Representation of the passive cooling system B: solar chimney associated with the earth-to-air heat exchanger, installed in an thermal zone (office room).

The three mathematical models are explained in the Section 3. In Section 4 , the case-study options are explored. The empirical parameters set for systems A and B and the method error analysis are included in Section 5.

\section{Modeling the systems}

\subsection{Earth-to-air heat exchanger (EAHE)}

The EAHE is a cylindrical pipe with diameter $D$ and extension $X$, buried at a depth $Z$. The EAHE was modeled using the analytical solution proposed by Hollmuller [9]. For a sinusoidal external temperature that enters the pipe, the model applies a dampening and a phase-shift to the entering signal, which is the external air temperature in the frequency domain. The function applied in the frequency domain of the external air temperature is a Fourier transform, obtaining the signal corresponding to the outlet air temperature (end of the pipe), which returns to the time domain, through the inverse 
Fourier Transform. Hollmuller [9] presents two solutions, for adiabatic and isothermal boundaries, which do not differ significantly for a sufficiently thick soil, according to the author. The latter is used in this work.

It is noteworthy that the analytical model does not account for variable air velocity in the pipe, even if when EAHE is associated with solar chimney the air flow rate is not mechanically controlled, so it varies during time. To overcome this limitation, a temperature profile is calculated for every air velocity, which depends on the incident solar radiation at the solar chimney. This approximative solution is far from solving the transient solution of the problem. However, this option is justified by the fact that the main objective is to test the applicability of the PCLR method, instead of validating the numerical models for EAHE systems.

The complete solution used to calculate the temperature profile at the end of the pipe is given by

$$
T_{v e}(X, t)=\theta_{0} \exp \left(-\frac{\pi D}{c_{a} \dot{m}_{a}} \tilde{h} X\right) \cos \left[\omega\left(t-\frac{X}{v_{p}}\right)-\frac{\pi D}{c_{a} \dot{m}_{a}} \tilde{k} X\right]
$$

where $\theta_{0}$ is the first temperature amplitude of the air input in the harmonic state, $\omega$ is the angular frequency of temperature oscillation, $D$ is the pipe diameter, $X$ is the pipe length, $c_{a}$ is the air isobaric thermal capacity, $\dot{m}_{a}$ is the mass airflow rate, $v_{p}$ is the air velocity inside the pipe, $\tilde{h}$ and $\tilde{k}$ are the amplitude dampening and the phase shift exchange coefficients of air/pipe and soil, respectively.

\subsection{Solar chimney $(S C)$}

The SC model lays on the work of Sakonidou et al. [10] for a SC south oriented. To determine the air velocity inside de SC the following relation is used [11] 


$$
v_{s c}=c_{D} \frac{\rho_{a}\left(T_{s c}\right)}{\rho_{a}\left(T_{i}\right)}\left[\frac{g Y \sin s\left(T_{s c}-T_{i}\right)}{T_{i}}\right]^{1 / 2}
$$

where $c_{D}$ represents the discharge coefficient, $T_{s c}$ the air temperature inside the SC, $T_{i}$ is the thermal zone air temperature, $g$ the gravitational acceleration, $\rho_{a}$ the air density as a temperature function, $Y$ and $s$ the height and the slope of the SC, respectively (see Fig. 3). The application of the model is limited to slope angles above $22^{\circ}$, since below that angle, the stack effect is insufficient.

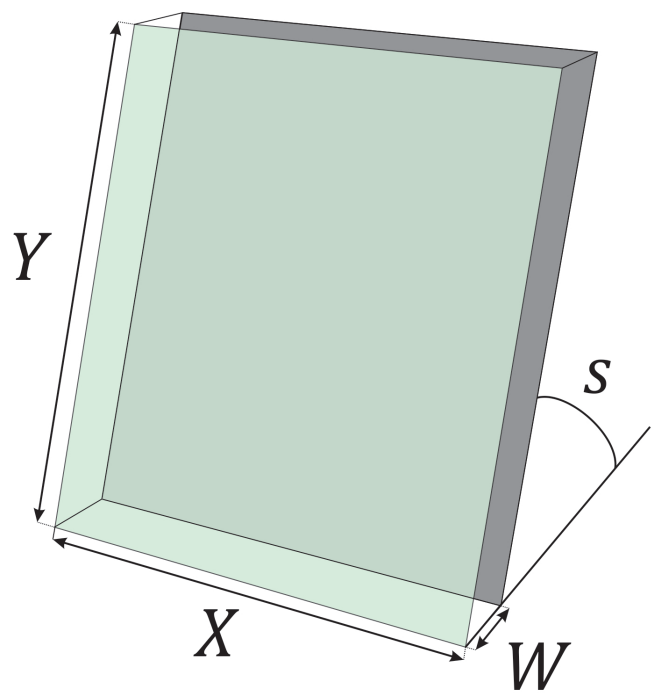

Figure 3: Solar chimney geometrical characteristics.

The optimum slope angle for the solar chimney, depends on the local latitude, according to Table 1 [12].

The original model of Sakonidou et al. [10] was modified in order to use hourly solar radiation available from weather climate data, instead of using calculation approximations. To determine the solar radiation absorbed by the SC black wall, the Snell formula was used 
Table 1: Optimum slope inclination for solar chimney depending on the local latitude.

\begin{tabular}{cc}
\hline Latitude (deg) & Optimum slope (deg) \\
\hline 0 & 55 \\
$5,10,15$ & 50 \\
$20,25,30$ & 45 \\
35,40 & 50 \\
45,50 & 55 \\
$55,60,65$ & 60 \\
\hline
\end{tabular}

$$
\frac{\eta_{a}}{\eta_{g l}}=\frac{\sin \beta_{r}}{\sin \beta_{i}}
$$

where $\eta_{a}$ and $\eta_{g l}$ are the refraction of air and glass, respectively, and $\beta_{i}$ and $\beta_{r}$ are the incidence and refraction angles, respectively. The three energy balance equations of $\mathrm{SC}$ at the temperature nodes $(T)$ black wall surface $(b w)$, glazed surface $(g l)$ and solar chimney air $(s c)$, respectively, are

$$
\begin{gathered}
\alpha_{b w} \tau_{g l} I A_{g l}=H_{b w}\left(T_{b w}-T_{e}\right)+h_{b w} A_{b w}\left(T_{b w}-T_{s c}\right)+\varepsilon_{b w} \sigma A_{g l}\left(T_{b w}^{4}-T_{g l}^{4}\right) \\
\alpha_{g l} I A_{g l}+\varepsilon_{b w} \sigma A_{g l}\left(T_{b w}^{4}-T_{g l}^{4}\right)=h_{g l} A_{g l}\left(T_{g l}-T_{s c}\right)+H_{g l}\left(T_{g l}-T_{e}\right) \\
h_{b w} A_{b w}\left(T_{b w}-T_{s c}\right)+h_{g l} A_{g l}\left(T_{g l}-T_{s c}\right)=2 c_{a} \dot{m}_{a}\left(T_{s c}-T_{i}\right)
\end{gathered}
$$

In the above equations, $\sigma$ is the Stephan-Boltzmann constant, $\alpha, \tau$ and $\varepsilon$ are the surface solar absorption, transmission and emissivity, respectively, $A$ is the surface area $\left(m^{2}\right), I$ is the surface solar irradiation $\left(W m^{-2}\right), H$ is the conductance between nodes $\left(W K^{-1}\right), h$ is the heat transfer coefficient 
$\left(W m^{-2} K^{-1}\right), c_{a}$ is the isobaric thermal capacity of air and $\dot{m}_{a}$ is the mass air flow rate.

The solve of the equations above requires the linearization of radiative terms, so it is assumed, as a first approximation that

$$
T_{b w}^{4}-T_{g l}^{4}=\left(T_{b w}-T_{g l}\right)\left(T_{b w}^{3}+T_{g l}^{3}\right)
$$

In the solving process, the sum of the cubic temperatures is considered as a constant and is iteratively updated. The heat transfer coefficients are calculated with the following approximations from [10]

$$
\begin{gathered}
h_{g l}=0.56 \frac{\lambda_{a}}{Y}\left(R a_{g l} \sin s\right)^{1 / 4} \\
h_{b w}=0.56 \frac{\lambda_{a}}{Y}\left(R a_{c} \sin s\right)^{1 / 4}+0.13\left(R a_{b w}^{1 / 3}-R a_{c}^{1 / 3}\right)
\end{gathered}
$$

with $\lambda_{a}$ the air thermal conductivity. The critical Rayleigh number, $R a_{c}$, designates the transition between laminar and turbulent flow and is obtained from the following approximation [10], with $s$ expressed in degrees,

$$
\log \left(R a_{c}\right)=8.9-0.00178(90-s)^{1.82}
$$

The relation presented in Eq. 14 is valid for $R a_{c}$ between 105 and 109 [13]. Moreover, only positive heat transfer coefficients were considered.

The Rayleigh number for glazing or black wall is obtained from

$$
R a_{g l \mid b w}=\frac{\left|T_{g \mid b w}-T_{i}\right|}{T_{i}} \frac{g \rho_{a}^{2} \operatorname{Pr} Y^{3}}{\mu^{2}}
$$

with $g$ the gravitational acceleration $\left(m^{2} / s\right), \operatorname{Pr}$ the Prandtl number, $\mu$ the air dynamic viscosity $\left(\mathrm{Kgm}^{-1} \mathrm{~s}^{-2}\right)$. 
The characteristics of SC elements, such as the glass and the black wall, are those adopted by Sakonidou et al. [10] (see Table 2). For the theoretical functioning of the SC only the upward flow is considered, which occurs whenever the air temperature inside the solar chimney is higher than the thermal zone air temperature. Otherwise a null air flow is assumed. The SC system has no time functioning restrictions, so it works whenever an upward flow is naturally induced by the stack effect.

\begin{tabular}{lcc} 
Table 2: Solar chimney thermo-physical characteristics \\
\hline Glass refraction index & $\eta_{g l}$ & 1.526 \\
Black wall solar absorption & $\alpha_{b w}$ & 0.9 \\
Black wall emissivity & $\varepsilon_{b w}$ & 0.95 \\
Black wall U-value $\left.{ }^{*}\right)\left[W K^{-1} m^{-2}\right]$ & $U_{b w}$ & 0.9 \\
Glass U-value $\left(^{*}\right)\left[W K^{-1} m^{-2}\right]$ & $U_{g l}$ & 9 \\
Discharge coefficient & $c_{D}$ & 0.57 \\
\hline
\end{tabular}

(*)excluding internal surface resistances.

\subsection{Cooling energy needs}

Energy needs are calculated making use of the 5R1C method from ISO 13790. $5 \mathrm{R} 1 \mathrm{C}$ is a simplified hourly method that allows computing the air temperature of a single thermal zone, $T_{i}$, and indirectly calculate the cooling or heating energy needs, $Q_{n d}$. The model consists of an equivalent electric circuit R-C (Resistance-Capacitance) connecting nodes of temperature. The analogy makes use of five conductances (inverse of the resistance) and one capacitance for the building thermal mass. The method assumes that solar gains are uniformly distributed among internal surfaces and internal air temperature is uniform within the thermal zone [5].

The 5R1C model is used to compute cooling energy needs in both cases: 
with and without passive cooling systems. In the former case, the 5R1C model is fully integrated with SC and EAHE models, already described in previous sections, by a connection between temperature nodes. Therefore, the supply air temperature of the thermal zone is a function of the outlet EAHE model and the external air temperature (Eq. 5 and Eq. 16) and the supply air temperature of the solar chimney ( $T_{i}$ in Eq. 11) is the internal air temperature of the thermal zone. Additionally, thermal zone airflow rate is calculated with the SC model. Fig. 4 schematically shows the nodes net used for modeling the thermal zone, which considers an extra conductance to disassemble air infiltration (external air) from air ventilation (EAHE outlet), changing the analogy to $6 \mathrm{R} 1 \mathrm{C}$ model.

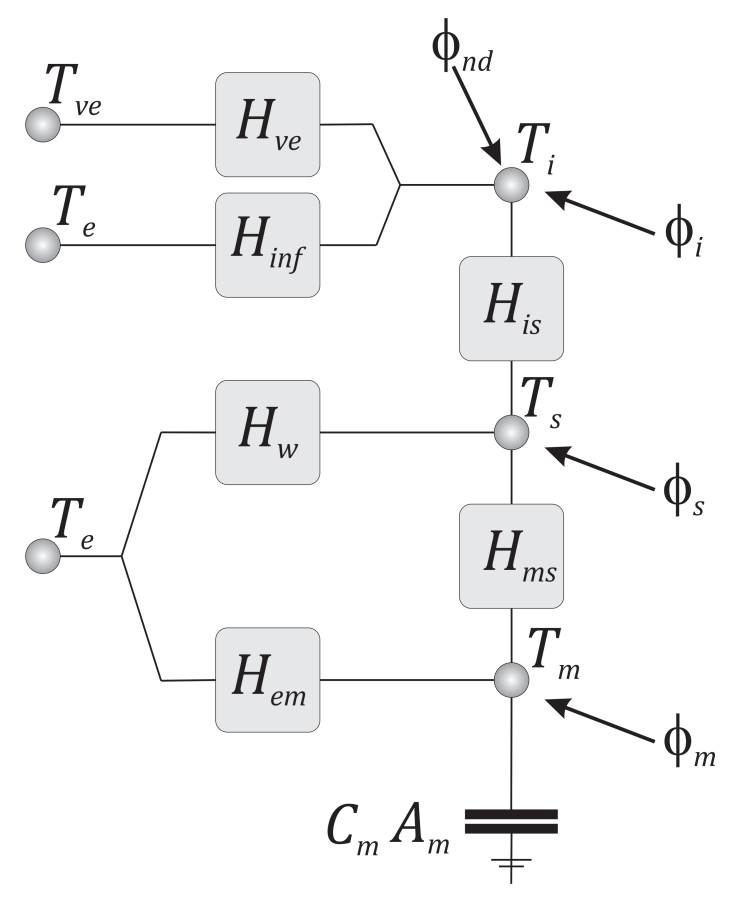

Figure 4: 6R1C model adapted from ISO 13790.

The matching between $6 \mathrm{R} 1 \mathrm{C}$ and $5 \mathrm{R} 1 \mathrm{C}$ is straightforward by applying the following equivalence for the equivalent supply air temperature 


$$
T_{\text {sup }}=\frac{H_{\text {inf }}}{H_{\text {inf }}+H_{v e}} T_{e}+\frac{H_{v e}}{H_{\text {inf }}+H_{v e}} T_{v e}
$$

The other main input variables for $5 \mathrm{R} 1 \mathrm{C}$ method are the external air temperature $T_{e}$, internal gains flow rate $\phi_{i n t}$, solar gains flow rate $\phi_{s o l}$, ventilation conductance $H_{v e}$, windows transmission conductance $H_{w}$ and opaque elements transmission conductance $H_{o p}$. The $5 \mathrm{R} 1 \mathrm{C}$ method uses a recursive formulation to estimate the thermal zone air temperature, in an hourly basis, by

$$
T_{i}=\frac{H_{i s} T_{s}+H_{v e} T_{s u p}+\phi_{i}+\phi_{n d}}{H_{i s}+H_{v e}}
$$

with $H_{i s}$ assumed as $15.53 \times A_{f}[5], \phi_{n d}$ the heat flow rate for cooling, $T_{s}$ the theoretical star temperature and $\phi_{i}$ the convective internal gain flow rate. These parameters are calculated with a set of equations which are further described in ISO 13970. Finally, the ventilation cooling potential $Q_{v e}$ is calculated from the hourly ventilation conductance $H_{v e, j}$ and the hourly temperature difference between supply and thermal zone conditions. Instead, the cooling energy needs is calculated from the hourly heat flow rate for cooling. $Q_{n d}$ and $Q_{v e}$ are both expressed in Joule $[J]$.

$$
\begin{gathered}
Q_{v e}=3600 \sum_{j} H_{v e, j}\left(T_{\text {sup }, j}-T_{i, j}\right) \\
Q_{n d}=3600 \sum_{j} \phi_{n d, j}
\end{gathered}
$$

\section{Case-study}

\subsection{Thermal zone}

The case-study is a room office from Solar XXI building [14] in Lisbon, Portugal, with no air conditioning system. The main façade is south oriented 
and the total area is covered by $42 \%$ of windows $(W W R=0.42)$. Besides solar shading devices and high thermal inertia, both passive cooling systems to control cooling load, an EAHE supplies cooled air by forced ventilation. Other office room characteristics are presented in Table 3. All partitions walls, ceiling and floor are considered adiabatic surfaces and, therefore, heat is transferred only by the external wall. The effect of photovoltaic panels, vertically installed in the external wall, are neglected for the thermal zone modeling. Shading devices are considered to be active at $100 \%$ of total glazing area. Typical office internal loads are accounted, from 8 a.m. to 5 p.m. every day, thus no weekends or holidays are taken into consideration in this analysis.

Table 3: Thermal zone characteristics

\begin{tabular}{lcc} 
Net floor area $\left[\mathrm{m}^{2}\right]$ & $A_{f}$ & 16.7 \\
Internal volume $\left[\mathrm{m}^{3}\right]$ & $V$ & 50.1 \\
External wall area $\left[\mathrm{m}^{2}\right]$ & $A_{o p}$ & 6.07 \\
Windows area $\left[\mathrm{m}^{2}\right]$ & $A_{w}$ & 4.43 \\
Windows U-value $\left[\mathrm{Wm}^{-2} \mathrm{~K}^{-1}\right]$ & $U_{w}$ & 4.5 \\
Wall U-value $\left[\mathrm{Wm}^{-2} \mathrm{~K}^{-1}\right]$ & $U_{o p}$ & 0.45 \\
Windows g-value & $g_{w}$ & 0.20 \\
Internal load $[W]$ & $\phi_{i n t}$ & 640 \\
Air infiltration $[\mathrm{ACH}]$ & - & 0.3 \\
Number of occupants & - & 2 \\
\hline
\end{tabular}

\subsection{Systems geometrical variations}

The models for systems A (EAHE) and B (EAHE+SC) consider a set of variations which are synthesized in Table 4 . 
Table 4: Parametric variations for earth-to-air heat exchanger and solar chimney systems.

\begin{tabular}{lcc} 
Geometrical parameter & & Range of validity $[m]$ \\
\hline Solar chimney height $[m]$ & $Y$ & {$[2-5]$} \\
Solar chimney width $[m]$ & $W$ & {$[0.80-2.50]$} \\
Air gap thickness of the solar chimney $[m]$ & $L$ & {$[0.10-0.40]$} \\
Solar chimney slope $[\mathrm{deg}]$ & $s$ & {$[40-90]$} \\
\hline Pipe diameter $[m]$ & $D$ & {$[0.15-0.40]$} \\
Pipe extension $[m]$ & $X$ & {$[10-20]$} \\
Buried pipe depth $[m]$ & $Z$ & {$[1.5-5]$} \\
Air flow rate $\left[m^{3} h^{-1}\right]$ & $\varphi_{v e}$ & {$[100-200]$} \\
\hline
\end{tabular}

Regarding solar chimney geometry, only geometrical solutions with widthto-height ratio higher than 0.3 were considered.

\subsection{Climate conditions}

Mediterranean climate conditions of six different Portuguese cities - Bragana, Porto, Coimbra, Lisboa, Évora and Faro - were considered at latitudes that vary from $42^{\circ}$ to $37^{\circ} \mathrm{N}$. Due to the fact that PCLR method works on a monthly basis, months from May to September were used to compute the pairs of values (PCLR, PCF). Climate parameters which characterize the six cities are presented in Table 5 for the month of July.

For the sake of simplicity, temperature values in Table 5 are presented in Celsius degrees, even if all calculations considered values in Kelvin degrees.

\section{Results}

\subsection{Ventilation cooling potential}

The term $Q_{v e}$ is computed from the results of hourly simulations by Eq. 18. However, in real applications this term should be computed making 
Table 5: Climate characteristics for the summer month of July.

\begin{tabular}{|c|c|c|c|c|c|}
\hline City & $\begin{array}{c}\text { Köppen } \\
\text { climate } \\
\text { classification }\end{array}$ & $\begin{array}{l}\text { Latitude } \\
\text { [deg] }\end{array}$ & $\begin{array}{c}\text { Mean global } \\
\text { solar irradiation, } \\
\bar{G}\left[W m^{-2}\right]\end{array}$ & $\begin{array}{c}\text { Mean } \\
\text { temperature, } \\
\bar{T}_{e}\left[{ }^{\circ} \mathrm{C}\right]\end{array}$ & $\begin{array}{l}\text { Mean temperature } \\
\text { amplitude, } \\
\overline{\Delta T}_{e}\left[{ }^{\circ} \mathrm{C}\right]\end{array}$ \\
\hline Bragança & Csb & 41.8 & 458 & 21.8 & 13.4 \\
\hline Porto & Csb & 41.2 & 416 & 19.1 & 8.7 \\
\hline Coimbra & $\mathrm{Csb}$ & 40.2 & 422 & 20.9 & 11.2 \\
\hline Lisboa & Csa & 38.7 & 453 & 22.5 & 13.6 \\
\hline Évora & Csa & 38.6 & 454 & 22.7 & 13.1 \\
\hline Faro & Csa & 37.0 & 478 & 24.2 & 11.0 \\
\hline
\end{tabular}

use of known parameters.

Therefore, from the simulations results, it is found that this term is correlated with geometrical and monthly mean climate parameters. The following empirical correlation should be used to get the ventilation cooling potential, expressed in Joule $[J]$,

$Q_{v e}=a_{1} D+a_{2} Z+a_{3} X+a_{4} \varphi_{v e}+a_{5} Y+a_{6} W+a_{7} L+a_{8} s+a_{9} \bar{T}_{e}+a_{10} \overline{\Delta T}_{e}+a_{11} \bar{G}+a_{12}$

where geometrical variables are defined in meters $[m]$, air temperature in Kelvin degrees $[K]$, volumetric air flow rate in $m^{3} h^{-1}$, solar chimney slope in degrees $[\mathrm{deg}]$ and mean global solar irradiation in $W^{-2}$. Empirical coefficients, obtained by best fitting, are presented in Table 6 .

\subsection{PCF correlations}

The empirical function that best fits the monthly simulation results is an exponential function of PCLR 
Table 6: Empirical coefficients for the ventilation cooling potential, $Q_{v e}$.

\begin{tabular}{lcccc}
\hline Coefficients & system A & \multicolumn{3}{c}{ system B } \\
& & B1 & B2 & B3 \\
& & $0.1 \leq L<0.2$ & $0.2 \leq L<0.3$ & $0.3 \leq L<0.4$ \\
$a_{1}\left(\times 10^{9}\right)$ & -0.0957 & -0.3670 & -0.3354 & -0.2925 \\
$a_{2}\left(\times 10^{5}\right)$ & -9.0012 & -8.3492 & -7.7549 & -7.3514 \\
$a_{3}\left(\times 10^{6}\right)$ & 3.9166 & 5.1814 & 4.5612 & 4.1553 \\
$a_{4}\left(\times 10^{6}\right)$ & 1.9831 & 0 & 0 & 0 \\
$a_{5}\left(\times 10^{7}\right)$ & 0 & 7.1217 & 5.8671 & 4.9643 \\
$a_{6}\left(\times 10^{9}\right)$ & 0 & 0.2155 & 0.3432 & 0.4950 \\
$a_{7}\left(\times 10^{9}\right)$ & 0 & 1.6510 & 0.7824 & 0.4686 \\
$a_{8}\left(\times 10^{6}\right)$ & 0 & 2.7572 & 3.4007 & 3.5975 \\
$a_{9}\left(\times 10^{7}\right) \bar{T}_{e} \leq 294 K$ & -2.0600 & 0.0895 & 0.9552 & 1.2979 \\
$a_{9}\left(\times 10^{7}\right) \bar{T}_{e}>294 K$ & -2.0300 & 0.0786 & 0.9322 & 1.3301 \\
$a_{10}\left(\times 10^{7}\right)$ & 0.5700 & 1.6545 & 1.8327 & 1.9135 \\
$a_{11}\left(\times 10^{5}\right)$ & 0 & 7.4109 & 8.7459 & 9.0003 \\
$a_{12}\left(\times 10^{9}\right)$ & 5.9519 & -1.0505 & -3.6685 & -4.8024 \\
\hline
\end{tabular}




$$
\mathrm{PCF}=1-e^{-k \cdot \vartheta\left(\bar{T}_{e}\right) \mathrm{PCLR}}=1-e^{-k \cdot \mathrm{PCLR}^{*}}
$$

with

$$
\vartheta\left(\bar{T}_{e}\right)=b_{1} e^{-b_{2}\left(\bar{T}_{e}-T_{0}\right)}
$$

and the empirical coefficients of Table 7 , considering $T_{0} \simeq 273.15 K$. It is noteworthy that correlations are obtained for mean monthly air temperature of $T_{0}+22 K$ and, therefore, $\vartheta\left(\bar{T}_{e}\right)=1$ for $\bar{T}_{e}=T_{0}+22 K$. PCLR $*$ in Eq. 21 and Fig. 5 is the corrected PCLR which is obtained by $\vartheta\left(\bar{T}_{e}\right)$.PCLR.

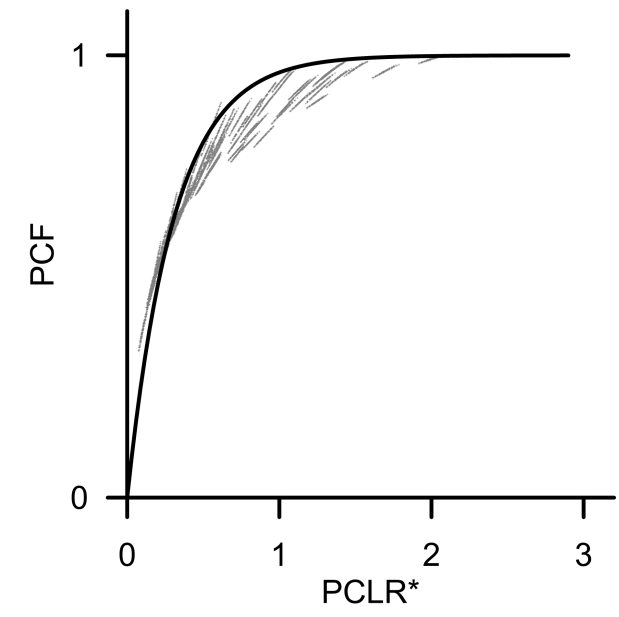

(a) System A

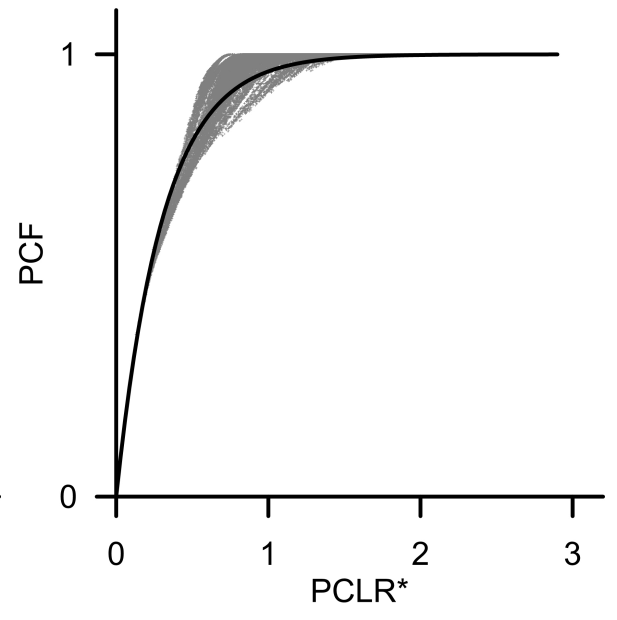

(b) System B2

Figure 5: Passive Cooling Fraction empirical functions compared to the numerical obtained for: a) System A, an earth-to-air heat exchanger (EAHE) and b) System B2, an EAHE associated with solar chimney (SC) with $0.2 \leq L<0.3$.

At this stage it is important to explore the physical meaning of the variables. The PCLR expresses the relationship between the cooling potential and the cooling energy load. When both terms are balanced $(\mathrm{PCLR}=1)$ the passive cooling system contributes to save approximately $1-e^{-k \cdot \vartheta\left(\bar{T}_{e}\right)}$ of the 
Table 7: Empirical coefficients for the Passive Cooling Fraction.

\begin{tabular}{lccccc} 
Coefficients & no system & system A & \multicolumn{3}{c}{ system B } \\
& & & B1 & B2 & B3 \\
& & & $0.1 \leq L<0.2$ & $0.2 \leq L<0.3$ & $0.3 \leq L<0.4$ \\
$k$ & 2.7063 & 3.0043 & 3.0257 & 3.2569 & 3.1953 \\
$b_{1}$ & 7.8225 & 175.31 & 25.8559 & 46.68 & 178.64 \\
$b_{2}$ & 0.0935 & 0.2348 & 0.1478 & 0.1747 & 0.2357 \\
\hline
\end{tabular}

cooling energy needs, for $k=1$ (an empirical parameter) at $T_{0}+22 K$, it means $63 \%$. Doubling the cooling potential relatively to the cooling energy load $(\mathrm{PCLR}=2)$, the passive cooling fraction for the same situation increases to $86 \%$.

This analysis reveals that the cooling potential is not totally 'used' to annul the cooling energy load. In a certain way, this is how the transient effects are integrated in the monthly method.

The coefficient $k$ is specific for each passive cooling system. The values obtained from the simulation modeling, in Table 7 , show that the cooling potential of system A and B is identical in terms of efficiency of 'utilization' (see Fig. 6 for range of $k$ values). But simulations running without passive cooling system besides natural air infiltration have resulted in to $k=2.7$ that is less efficient than systems $\mathrm{A}$ and $\mathrm{B}$ (with $k$ above 3 ).

The temperature correction $\vartheta\left(\overline{T_{e}}\right)$ to PCLR applies only for mean monthly external air temperature different from $T_{0}+22 \mathrm{~K}$, higher values for external air temperature reduce the PCF of the system, thus its efficiency (see Fig. 7).

It is noteworthy to comment the PCF functions obtained for the different systems. Apparently, for higher external air temperatures, the no system option could be more efficient than the studied systems. However, for the no 


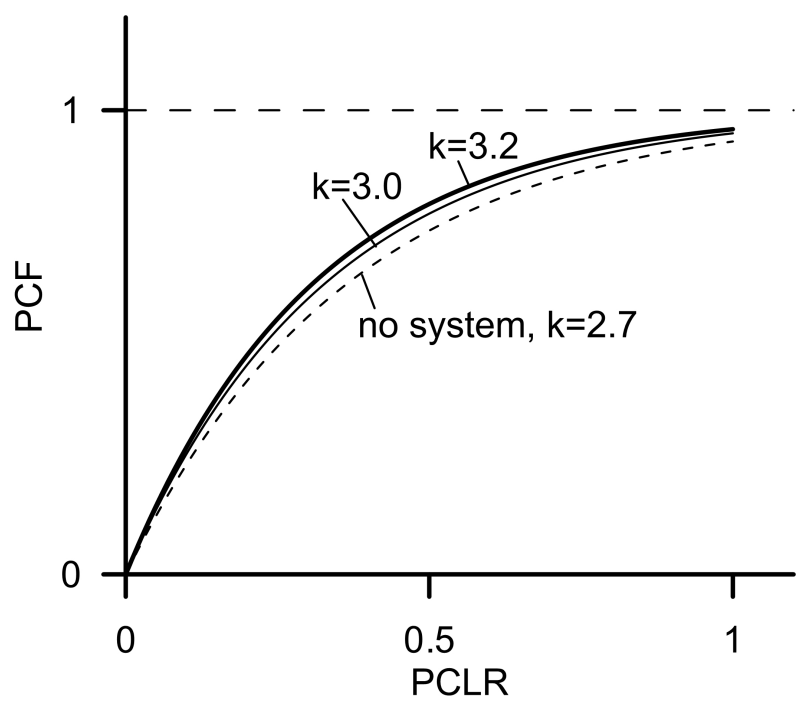

Figure 6: Passive Cooling Fraction empirical functions, at $T_{0}+22 \mathrm{~K}$, for Passive Cooling Systems characterized by different $k$ values.

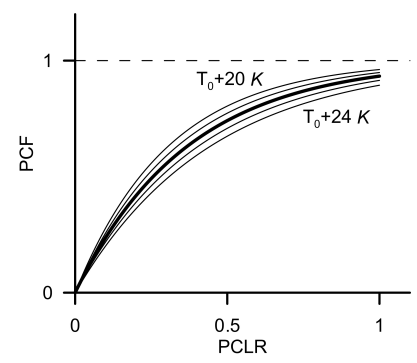

(a) No System

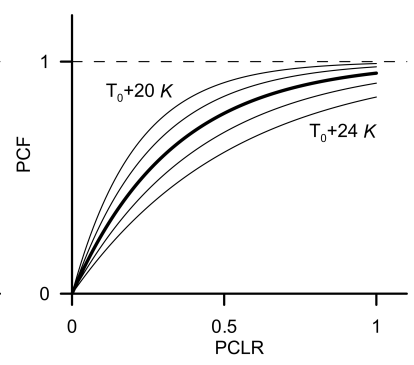

(b) System A

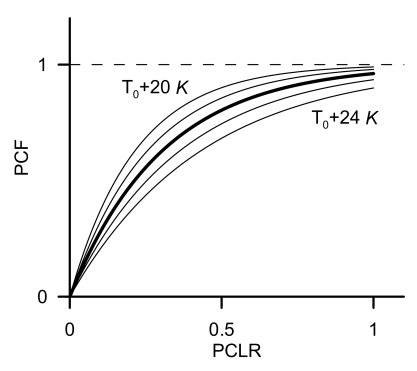

(c) System B2

Figure 7: Passive Cooling Fraction empirical functions for different values of monthly mean air temperature, $\bar{T}_{e}$ and for: a) No system, b) System A, an earth-to-air heat exchanger (EAHE) and c) System B2, an EAHE associated with solar chimney (SC) with $0.2 \leq L<0.3$. 
system option it is harder to obtain higher values of PCLR because it comes from the ratio between cooling potential and cooling energy loads. This fact is explored in the example of application (Sec. 5.4).

\subsection{Error analysis}

Considering all the $N$ tested cases for each system, the error analysis takes into account two normalized parameters, the bias and the error, using for normalization the cooling energy load $Q_{g n}$, shown in Table 8 and, respectively, obtained by

$$
\begin{gathered}
\hat{\mu}=\frac{1}{N} \sum\left(\hat{Q}_{n d, \mathrm{PCLR}}-\hat{Q}_{n d, \mathrm{NUM}}\right) \\
\hat{\sigma}=\sqrt{\frac{1}{N} \sum\left(\hat{Q}_{n d, \mathrm{PCLR}}-\hat{Q}_{n d, \mathrm{NUM}}\right)^{2}}
\end{gathered}
$$

From the error analysis, it can be concluded that PCLR slightly underestimates normalized cooling energy needs $\left(\hat{Q}_{n d}=Q_{n d} / Q_{g n}\right)$ by $1.6 \%$ for EAHE system. On the other hand, PCLR overestimates normalized cooling energy needs when the solar chimney is associated with the EAHE, from $1.8 \%$ to $2.6 \%$, depending on the air gap solar chimney width.

For the considered systems, the error does not overcome $5.2 \%$, which is an acceptable variation for simplified methods. Note that the errors can invariably apply to the normalized cooling energy needs and PCF, obtained by $1-\hat{Q}_{n d}$.

\subsection{Example of application}

The PCLR method is here applied to calculate energy savings by using the EAHE system for the office room described in Section 4.1 for the month of July in Lisbon (see Table 5). Internal and solar gains are, for that monthly 
Table 8: Normalized errors of PCLR method.

\begin{tabular}{lccc} 
System & Number of & bias & error \\
& cases, $N$ & $\hat{\mu}$ & $\hat{\sigma}$ \\
\hline A & 8400 & $-1.6 \%$ & $4.3 \%$ \\
B1 & 145152 & $2.6 \%$ & $5.2 \%$ \\
B2 & 145152 & $2.3 \%$ & $3.6 \%$ \\
B3 & 145152 & $1.8 \%$ & $2.9 \%$ \\
\hline
\end{tabular}

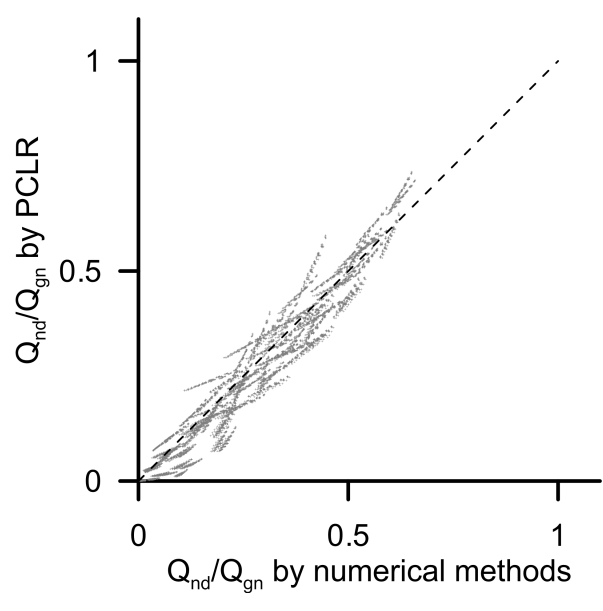

(a) System A

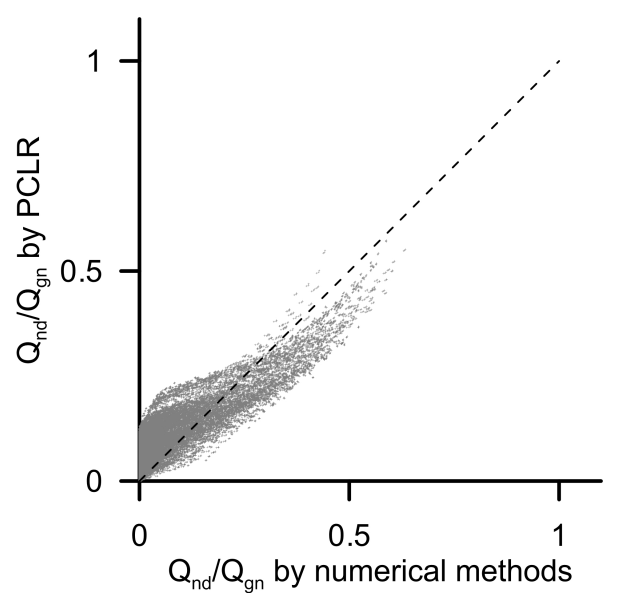

(b) System B2

Figure 8: Normalized cooling energy needs by PCLR compared to the numerical method obtained for: a) System A, an earth-to-air heat exchanger (EAHE) and b) System B2, an EAHE associated with solar chimney (SC) with $0.2 \leq L<0.3$. 
period, $Q_{g n}=1010 M J$. Without passive cooling systems, the cooling energy needs are $Q_{n d}=662 \mathrm{MJ}$. Note that air infiltration and thermal losses through the external envelope naturally contribute to a PCF of $34 \%$, which is equivalent of a PCLR ${ }^{*}$ of $16 \%\left(\vartheta\left(\bar{T}_{e}\right)=0.95\right)$, as shown in Fig. 9.

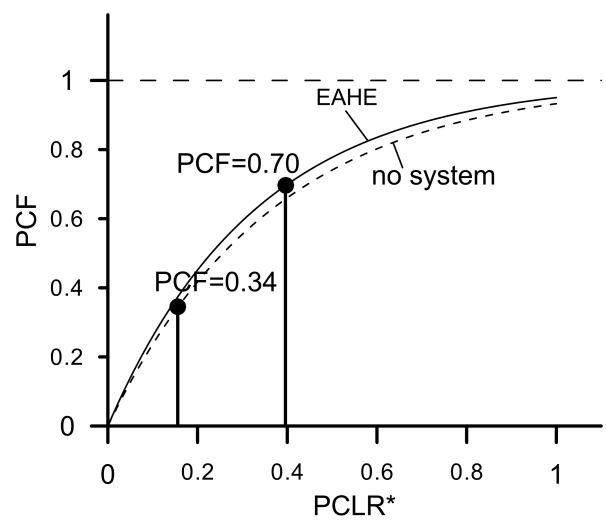

Figure 9: $\mathrm{PCF}$ and $\mathrm{PCLR}^{*}$ calculated for the example of application with no system and making use of EAHE.

The EAHE is characterized by a diameter of $D=0.30 \mathrm{~m}$, an extension of $X=15 \mathrm{~m}$ and a buried depth of $Z=5 \mathrm{~m}$. The fan air flow rate is $\varphi_{v e}=200 \mathrm{~m}^{3} h^{-1}$. For this specific EAHE and for the month of July, the estimated cooling ventilation potential is $Q_{v e}=450 \mathrm{MJ}$ (applying Eq. 20).

Therefore, at $T_{0}+22 \mathrm{~K}$, PCLR is $45 \%$. Applying the temperature correction, $\mathrm{PCLR}^{*}$ equals $40 \%\left(\vartheta\left(\bar{T}_{e}\right)=0.89\right)$, achieving a PCF of $70 \%$ (Fig. 9$)$, which leads to $Q_{n d}=307 M J$.

From this example, it can be concluded that the EAHE contribution to decrease cooling energy needs is about $50 \%$.

\section{Conclusions}

The application of an innovative method for calculating the cooling energy needs of two systems, an earth-to-air heat exchanger with forced ventilation 
and an earth-to-air heat exchanger associated with a solar chimney, have shown that:

- the Passive Cooling Fraction (PCF) correlates with a temperature corrected PCLR, PCLR ${ }^{*}$, by a function of the type $1-e^{-k \cdot \text { PCLR }^{*}}$;

- PCF, a physical parameter for the system efficiency, decreases with the increase of the monthly mean value of external air temperature;

- PCLR slightly underestimates normalized cooling energy needs by $1.6 \%$ for EAHE system;

- PCLR slightly overestimates normalized cooling energy needs when the solar chimney is associated with the EAHE, from $1.8 \%$ to $2.6 \%$, depending on the air gap solar chimney width.

- for all cases, the PCLR method error (normalized standard deviation) is below $5.2 \%$ when comparing to the hourly numerical results.

Considering the above, the newly developed method gives an estimative of the cooling energy needs with the approximation required by simplified methods. This simplified method can contribute to improve monthly cooling energy needs calculations of ISO 13790, whenever passive cooling systems are used.

\section{Nomenclature}

$a$ empirical constant

$b$ empirical constant

$c$ isobaric thermal capacity $\left(\mathrm{Jkg}^{-1} \mathrm{~K}^{-1}\right)$ 
$c_{D}$ discharge coefficient

$g$ gravitational acceleration $\left(m s^{-2}\right)$

$\tilde{h}$ amplitude dampening exchange coefficient of air/pipe+soil $\left(W K^{-1} m^{-2}\right)$

$h$ heat transfer coefficient $\left(W K^{-1} m^{-2}\right)$

$\tilde{k}$ phase shift exchange coefficient of air/pipe+soil $\left(W K^{-1} m^{-2}\right)$

$k$ empirical constant

$\dot{m}_{a}$ mass air flow rate $\left(\mathrm{kgm}^{-3}\right)$

$v$ velocity $\left(m s^{-1}\right)$

$s$ solar chimney slope $(\mathrm{deg})$

$A$ surface area $\left(m^{2}\right)$

$D$ pipe diameter $(m)$

$G$ global solar irradiation $\left(W m^{-2}\right)$

$H$ thermal conductance $\left(W K^{-1}\right)$

$I$ surface solar irradiation $\left(W m^{-2}\right)$

$N$ number of cases

PCLR Passive Cooling Load Ratio

PCLR* $^{*}$ temperature corrected PCLR

PCF Passive Cooling Fraction

$\operatorname{Pr}$ Prandtl number 
$Q$ heat energy $(J)$

$Q_{g n}$ cooling energy load $(J)$

$Q_{n d}$ cooling energy needs $(J)$

$Q_{v e}$ ventilation cooling potential $(J)$

Ra Rayleigh number

$T$ air or surface temperature $(K)$

$T_{0}$ absolute temperature at $0^{\circ} \mathrm{C}(K)$

$U$ overall heat transfer coefficient $\left(W K^{-1} m^{-2}\right)$

$V$ volume $\left(m^{3}\right)$

$X$ pipe extension $(m)$

$Y$ solar chimney height $(m)$

$Z$ buried pipe depth $(m)$

Greek letters

$\alpha$ surface solar absorption

$\beta_{i}$ angle of incidence $(\mathrm{deg})$

$\beta_{r}$ angle of refraction $(\mathrm{deg})$

$\varepsilon$ surface emissivity

$\eta$ refraction index

$\theta_{0}$ first air temperature amplitude in the harmonic state 
$\vartheta$ temperature function

$\lambda$ thermal conductivity $\left(W K^{-1} m^{-1}\right)$

$\mu$ dynamic air viscosity $\left(\mathrm{kgm}^{-1} \mathrm{~s}^{-1}\right)$

$\hat{\mu}$ normalized error mean value, bias

$\rho_{a}$ air density

$\sigma$ Stephan-Boltzman constant

$\hat{\sigma}$ normalized error standard deviation, error

$\tau$ surface solar transmission

$\phi$ heat flow rate $(W)$

$\varphi$ volumetric air flow rate $\left(\mathrm{m}^{3} \mathrm{~s}^{-1}\right)$

$\omega$ angular frequency of temperature oscillation $\left(\mathrm{rads}^{-1}\right)$

$\Delta T$ thermal amplitude $(K)$

Subscripts

a air

bw black wall surface

c critical

e external air

f floor

i air inside the thermal zone 
int internal

is internal-to-star

inf infiltration air

j hour

NUM numerical methods

op opaque element

$\mathbf{p}$ air inside the pipe

PCLR PCLR method

gl glass surface

s star

sc air inside the solar chimney

sol solar

sup supply air

ve ventilation air

w window

\section{References}

[1] L. Pérez-Lombard, J. Ortiz, C. Pout, A review on buildings energy consumption information, Energy and Buildings, 40 (2008) 394-398.

[2] Final energy consumption by sector (CSI 027/ENER 016), Assessment published Mar 2012, www.eea.eropa.eu. 
[3] E. Musall, T. Weiss, K. Voss, A. Lenoir, Net Zero Energy Solar Buildings: An Overview and Analysis on Worldwide Building Projects, in: Proceedings EuroSun Conference, Graz, Austria, 2010.

[4] CEC, Energy Performance of Building Directive, Directive 2010/31/EU, Official Journal of the European Communities (2010) 1335.

[5] ISO 13790, Energy Performance of Buildings, Calculation of Energy Use for Space Heating and Cooling, 2008.

[6] M.J.N. Oliveira Panão, H.J.P. Gonçalves, Methodological development of seasonal cooling energy needs by introducing ground-cooling systems, in: Proceedings of the 27th International conference on Passive and Low Energy Architecture, Architecture and Sustainable Development, Vol I, 645-650, Louvain-la-Neuve, Belgium, 2011.

[7] J.D. Balcomb, Development of simplified design aids based on the results of simulation analysis, in: International Colloquium on Passive Solar House Testing, Nice, France, 1980.

[8] H. van Dijk, M. Spiekman, P. de Wilde, A monthly method for calculating energy performance in the context of European building regulations, in: Proceedings of Ninth International IBPSA Conference Montral, Canada, 2005.

[9] P. Hollmuller, Analytical characterization of amplitude-dampening and phase-shift in air/soil heat-exchangers, International Journal of Heat and Mass Transfer, 46 (2003) 4303-4317.

[10] E.P. Sakonidou, T.D. Karapantsios, A.I. Baloukts, D. Chassapis, Modeling of the optimum tilt of a solar chimney for maximum air flow, Solar Energy, 82 (2008) 80-94. 
[11] E.P. Sakonidou, T.D. Karapantsios, A.I. Baloukts, D. Chassapis, Corrigendum to Modeling of the optimum tilt of a solar chimney for maximum air flow, Solar Energy, 86 (2012) 809.

[12] R. Khanal, L. Chengwang, Solar chimney-A passive strategy for natural ventilation, Energy and Buildings, 43 (2010) 1811-1819.

[13] D. VDI-Verlag GmbH. VDI Heat Atlas. Springer. 1993.

[14] M.J.N. Oliveira Panão, H.J.P. Gonçalves, Solar XXI building: proof of concept or a concept to be proved?, Renewable Energy, 36 (2011), 2703-2710. 